\section{Jurnal Kimia Sains dan Aplikasi Journal of Scientific and Applied Chemistry}

Journal homepage: http://ejournal.undip.ac.id/index.php/ksa

\title{
Utilization of Rice Husk Cellulose as a Magnetic Nanoparticle Biocomposite Fiber Source for the Absorption of Manganese $\left(\mathrm{Mn}^{2+}\right)$ Ions in Peat Water
}

\author{
Emil Zacky Effendi ${ }^{a, 1}$, Yudhi Christian Hariadi ${ }^{a, 2}$, Muhammad Daffa Salaahuddin $^{a, 3}$, \\ Chairul Irawan ${ }^{a, 4}$, Iryanti Fatyasari Nata ${ }^{a, 5,},{ }^{*}$ \\ ${ }^{a}$ Chemical Engineering, Lambung Mangkurat University, Banjarbaru, South Kalimantan, Indonesia \\ Author emails: 1.emilzacky255@gmail.com; 2.yudhichristianharyadi98@gmail.com; 3.daffaupa213@gmail.com; \\ 4.cirawan@ulm.ac.id; 5,*ifnata@ulm.ac.id
}

https://doi.org/10.14710/jksa.22.6.220-226

\section{Article Info \\ Article history: \\ Received: $3^{\text {rd }}$ July 2019 Revised: $17^{\text {th }}$ September 2019 \\ Accepted: $1^{\text {st }}$ October 2019 \\ Online: $30^{\text {th }}$ November 2019}

Keywords:

rise husk fiber; adsorbent;

biocomposite; $\mathrm{Mn}^{2+}$ ion

\begin{abstract}
Rice husk (RH) is an agricultural waste that contains cellulose. Rice husk fiber (RHF) can be used as a source of fiber in the manufacture of magnetic nanoparticle biocomposite. The purpose of this study is to synthesize and characterize magnetic nanoparticle biocomposite used as an adsorbent and evaluate its performance on the adsorption of $\mathrm{Mn}^{2+}$ ions and Total Suspended Solid (TSS) in peat water. Rice husk fiber was delignified to eliminate lignin levels. Furthermore, the biocomposite was made through the solvothermal method with and without the addition of hexanediamine. The products produced are two types of adsorbents, namely magnetic nanoparticle biocomposite with an amino group (RHB-MH) and rice husk fiber biocomposite without an amino group (RHB-M). These biocomposites were used to adsorb $\mathrm{Mn}^{2+}$ ions in peat water. Evaluations were carried out at $\mathrm{pH} 5,6,7$, and 8 with an optimum adsorption time of 60 minutes. The solutions at the time of adsorption were evaluated to determine the optimum conditions of the adsorption process carried out. The observation of magnetic nanoparticle biocomposite based on the analysis of Scanning Electron Microscopy (SEM) shows magnetic nanoparticles formed on the surface of rice husk fiber with a diameter of 30-50 nm. X-Ray Diffraction (XRD) analysis showed that the delignification of rice husk increased Crystallinity Index (CrI) by $64.98 \%$ and reduced silica content by $78 \%$. Fourier Transform Infra-Red (FT-IR) spectrometer show absorption peak at $570 \mathrm{~cm}^{-1}$ for $\mathrm{Fe}-\mathrm{O}$ bonds and $\mathrm{Fe}_{3} \mathrm{O}_{4}$ peak around $1627 \mathrm{~cm}^{-1}$, indicating the presence of $\mathrm{N}-\mathrm{H}$ bending. The optimum condition for $\mathrm{Mn}^{2+}$ adsorption was achieved at $\mathrm{pH} 5$ and 60-minutes duration with an adsorption capacity of 54.7 $\mathrm{mg} / \mathrm{g}$ and $190.78 \mathrm{mg} / \mathrm{g}$ for RHB-M and RHB-MH. The TSS reduction achieved the effectiveness of $60.2 \%$ and $90.3 \%$ for BSP-M and BSP-MH, respectively.
\end{abstract}

\section{Introduction}

South Kalimantan is a region with a vast area of swamps or peatlands. This peat water is murky, smelly, and brackish, in which one of the causes is the high level of manganese metal ions $\left(\mathrm{Mn}^{2+}\right)$ present in the water. Peat water holds high levels of metal ions such as ferrous (Fe) and manganese $(\mathrm{Mn})$ metals. Due to the presence of manganese deposits, stain will generally develop on white materials. Based on the effect caused by the conditions of the peat water, treatment is, therefore, necessary to be done to transform peat water into a suitable form for various uses. One of the processing techniques available is the use of adsorbents that can bind metal ions and reduce the level of turbidity and acidity of peat water. 
The ability of adsorbents to bind metal ions is strongly influenced by their characteristics. An approach to construct a suitable adsorbent is the manufacture of absorbent in the form of composites. Composite is a macroscopic mixture of two or more materials to produce new material. Composite materials have substantial advantages such as its lightweight and better mechanical properties, especially as a part of constituent materials in the aircraft industry [1]. Another advantage of composite materials is that the technology used in the manufacture is relatively simple, with low production costs that can minimize the use of basic and generic materials. However, composites harbor weaknesses such as the high cost of raw materials, sensitive to moisture and temperature, and are susceptible to damage in its single layered area $[2,3]$.

One of the materials that can make up a composite material is magnetic nanoparticles. The properties that the material possesses ground composite material to have more value as a result of its consequent size in the nanometer range and larger surface area while other materials added function as a matrix or magnetic dwelling for deposited nanoparticles to form a composite. Magnetic nanoparticles have been used in several fields such as magnetic storage [4], immunoassay [5], and as an adsorbent [6]. Production of magnetic nanoparticles through the solvothermal method produces stable particles, uniform in size, and has a high degree of magnetification, demonstrating its potential to be further developed [ 7,8$]$. The use of biomass-based adsorbents is an effective form of waste utilization because it can easily be obtained and is widely available in nature $[9,10]$.

The use of modified rice husk as an ingredient as an adsorbent has been investigated for $\mathrm{Fe}, \mathrm{Cu}$ and $\mathrm{Ni}$ ions [11]; thus, a further study of the ability of adsorption for other ions, especially manganese ions $\left(\mathrm{Mn}^{2+}\right)$, is imperative. The ability of magnetic nanoparticle biocomposites to adsorb $\mathrm{Mn}^{2+}$ ions can be assessed in terms of various $\mathrm{pH}$ conditions of peat water and the ability to degrade TSS contained in peat water.

\section{Methodology}

\subsection{Materials}

The materials used in this experiment are rice husks and peat water taken from the Peat area, Banjar Regency, South Kalimantan, ethylene glycol $\left(\mathrm{C}_{6} \mathrm{H}_{6} \mathrm{O}_{2}\right.$, pa), sodium acetate anhydrous $\left(\mathrm{C}_{2} \mathrm{H}_{3} \mathrm{NaO}_{2}\right.$, pa), manganese (II) chloride tetrahydrate $\left(\mathrm{MnCl}_{2} .4 \mathrm{H}_{2} \mathrm{O}\right.$, pa) hexanediamine (pa), and sodium hydroxide $(\mathrm{NaOH}, \mathrm{pa})$ from Sigma Aldrich. Besides, hydrochloric acid ( $\mathrm{HCl}$, technical) and ethanol $\left(\mathrm{C}_{2} \mathrm{H}_{5} \mathrm{OH}\right.$, technical) produced by UPT BPPTK LIPI.

\subsection{Delignification of Rice Husk}

Rice husk was washed and dried for seven days, then crushed using a blender and sieved to 60 mesh in size. Dry rice husk powder was then soaked for 2 hours in $1 \% \mathrm{NaOH}$, heated at $80^{\circ} \mathrm{C}$ and stirred at $100 \mathrm{rpm}$ for 2 hours. The powder was later washed until the filtrate reached a neutral $\mathrm{pH}$ and dried. The produced fiber is indicated as RH-D.

\subsection{Synthesis of Magnetic Nanoparticle Biocomposite}

Ethylene glycol $(24 \mathrm{~mL})$ added with sodium acetate anhydrous ( $1.6 \mathrm{~g}$ ) and iron (III) chloride ( $0.8 \mathrm{~g}$ ) were stirred for 10 minutes at $50^{\circ} \mathrm{C}$. Into the mixture, $1,6-$ hexanediamine $(7 \mathrm{~mL})$ and rice husk cellulose $(0.5 \mathrm{~g})$ were added, followed by stirring for 5 minutes. The mixture was placed in a Teflon Stainless Steel Autoclave and then put in an oven at $200^{\circ} \mathrm{C}$ for 6 hours. Once the process was done, the reactor was cooled to room temperature, and the mixture was washed with distilled water and ethanol to remove any residual chemicals that did not part take in the reaction. The biocomposite product with the addition of hexanediamine (RHB-MH) was stored in the distilled water, ready for use. Iron (III) chloride was added as a precursor in the formation of magnetic nanoparticles that would subsequently form a composite with rice husk cellulose. A biocomposite as a comparative control was synthesized through the same process, though without the addition of hexanediamine (RHB-M). The process of separating the magnetic nanoparticle biocomposite from the solution involved the use of an external magnet, in which the biocomposite interacted, approached, or attached to a magnetic source coming from outside because of the attraction between the magnetic poles. SEM, XRD, and FT-IR characterizations were carried out at each stage of the process to determine morphological and structural changes that occurred.

\subsection{Adsorption Process}

Peat water samples (200 $\mathrm{mL})$ with varying $\mathrm{pH}(5,6,7$ and 8) condition were combined with magnetic nanoparticle biocomposite adsorbent $(0.15 \mathrm{~g})$ and placed on a shaker at a speed of 100 rpm for 15, 30, 60, 120 and 240 minutes for the two types of adsorbents synthesized. After the set adsorption time was reached, the solution was separated and was analyzed for its manganese ion content through the Atomic Absorption Spectroscopy (AAS) method. At this stage, the optimum adsorption time was determined to be then used for all $\mathrm{pH}$ variations (5, 6, 7, and 8). As a control, a rice husk fiber adsorbent, which has been delignified, was also used.

\subsection{Characterization}

Characterizations of magnetic nanoparticle biocomposite were carried out through Scanning Electron Microscope (SEM, JEOL, JSM-6500 LV), X-Ray Diffraction (XRD, Rigaku D/MAX-B X-ray diffractometer) with Cooper $\mathrm{K}$-alpha $(\mathrm{Cu} \mathrm{K \alpha})$ beam, $2 \theta=$ $10-40^{\circ}$ and a scan rate of $2^{\circ} \mathrm{min}^{-1}$. Analysis through Fourier Transform Infra-Red spectroscopy (FT-IR, Biorad, Digilab FTS-3500) was also done at a wavelength of $4000-400 \mathrm{~cm}^{-1}$ with a scan rate of 8 . 


\subsection{Total Suspended Solid (TSS) Analysis}

Analysis of TSS content with ASTM D 5907-09 Standard Test Method for Filterable and Nonfilterable Matter in Water was done through filtering as much as 50 $\mathrm{mL}$ sample with filter paper that had been weighed. The filter paper would then be cooled in a desiccator and weighed. The same procedure was repeated until the weight produced was constant.

$\frac{(A-B)}{V}$

TSS $=$

Descriptions:

TSS = Total Suspended Solid (\%);

$\mathrm{A}=$ mass of filter paper + dry residue $(\mathrm{mg})$;

$\mathrm{B}=$ mass of filter paper (mg);

$\mathrm{V}=$ sample volume

\section{Results and Discussion}

\subsection{Characterization of Magnetic Nanoparticle} Biocomposite

Rice husk (RH) is a type of lignocellulose that possesses a complex structure. The delignification process done to the rice husk would produce a different color to the rice husk. Where the initial brown rice husk would turn gray after the delignification process, as shown in Figure 1.

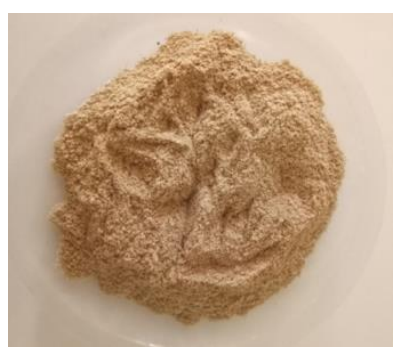

a

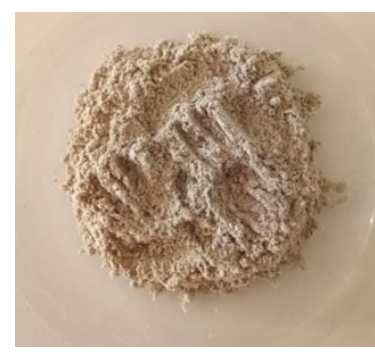

b
Figure 1. Rice husk powder (a) before treatment and (b) after treatment

Based on the SEM results, the surface of the rice husk fiber (Figure 2a) formed a lump identified as silica, which is concentrated at a certain point [12]. The delignification of rice husk fiber resulted in the decomposition of silica, lignin, and hemicellulose contained in lignocellulose. The silica contained in rice husk decreased from $29 \%$ to $3.6 \%$ after the delignification process, as identified with an Energy Dispersive X-Ray Analyzer (EDX) obtained concurrently in SEM analysis. This made the surface of the rice husk fiber smoother. The results of the elemental analysis of each sample with EDX are shown in Table 1.

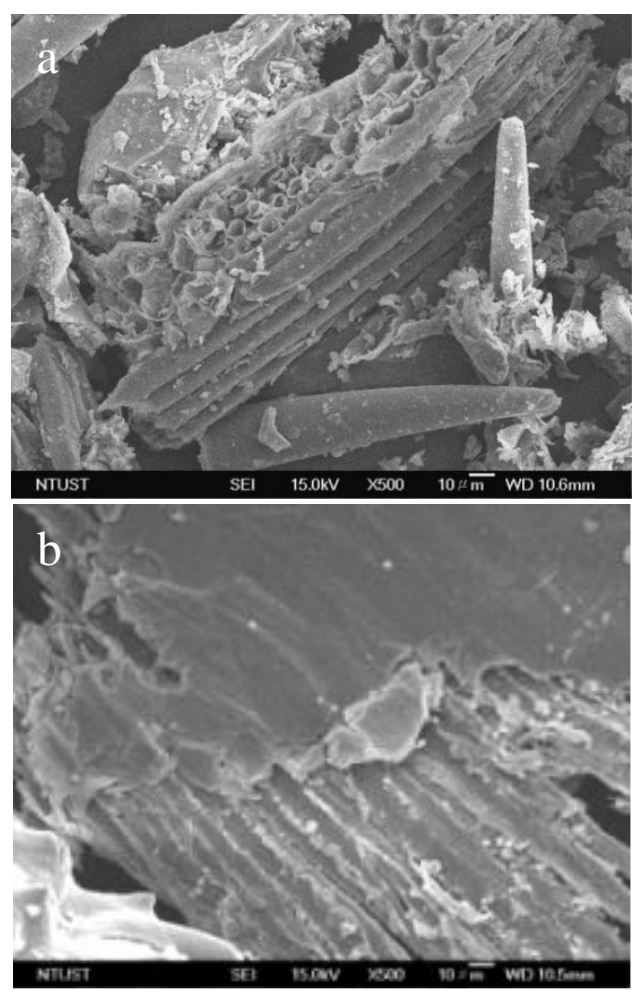

Figure 2. SEM image of rice husk fiber (a) before treatment and (b) after treatment

Table 1. EDX analysis results of RH, RH-D, RHB-M, and RHB-MH

\begin{tabular}{cccccc}
\hline \multirow{2}{*}{ Sample } & \multicolumn{5}{c}{ Element (Mass \%) } \\
\cline { 2 - 6 } & $\mathrm{Si}$ & $\mathrm{C}$ & $\mathrm{N}$ & $\mathrm{O}$ & $\mathrm{Fe}$ \\
\hline $\mathrm{RH}$ & 29.0 & 23.63 & - & 47.37 & - \\
$\mathrm{RH}-\mathrm{D}$ & 3.60 & 50.65 & - & 45.75 & - \\
$\mathrm{RHB}-\mathrm{M}$ & - & 14.91 & - & 35.73 & 49.36 \\
$\mathrm{RHB}-\mathrm{MH}$ & - & 19.01 & 2.44 & 36.38 & 42.17 \\
\hline
\end{tabular}

Figure 3 shows the morphological structure of magnetic nanoparticle biocomposite with and without the addition of hexanediamine, where $\mathrm{Fe}_{3} \mathrm{O}_{4}$ particles have formed on the surface of RHB-M and RHB-MH. The addition of hexanediamine gave a different result in the $\mathrm{Fe}_{3} \mathrm{O}_{4}$ particles, which are smaller in size at around $30 \mathrm{~nm}$ (Figure $3 \mathrm{~b}$ ). The results obtained are in accordance with previous researches in magnetite formation $[8,13,14]$. In the process of the formation of $\mathrm{Fe}_{3} \mathrm{O}_{4}$, hexanediamine plays an essential role in defining the particle size. The amino group contained in hexanediamine inhibits the growth of $\mathrm{Fe}_{3} \mathrm{O}_{4}$ from $\mathrm{FeCl}_{3}$. When $\mathrm{Fe}_{3} \mathrm{O}_{4}$ is formed, amino groups are deposited on the particle surface and inhibit the growth of $\mathrm{Fe}_{3} \mathrm{O}_{4}$ because it hampers ferric ions from entering the particle nucleus [13]. The formation of magnetic nanoparticles in biocomposites was analyzed by EDX in which ions contained in RHB- $M$ was $49.36 \%$, and RHB-MH was $42.17 \%$. The addition of hexanediamine was indicated by the $\mathrm{N}$ content of RHB-MH at $2.44 \%$. 


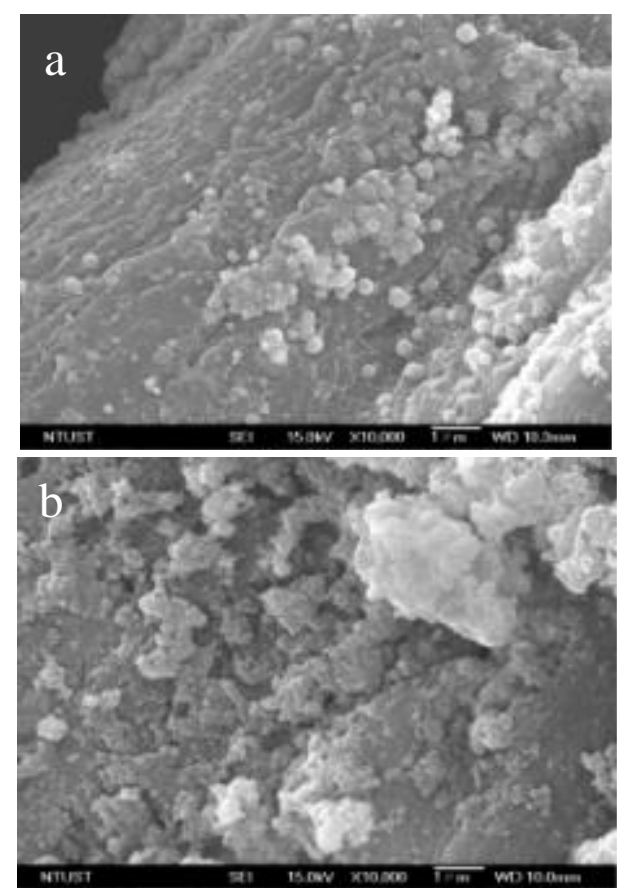

Figure 3. SEM images of (a) rice husk biocomposite fiber without an amino group (RHB-M) and (b) rice husk fiber biocomposite with an amino group (RHB-MH).

Cellulose crystal structure and Crystallinity Index (CrI) of rice husk before and after delignification can be analyzed by XRD. Cellulose crystal at an angle of $2 \theta$ between $20^{\circ}-80^{\circ}$ displays dominant peaks [15]. XRD data were used to calculate $\mathrm{CrI}$, where the highest crystal intensity was taken in each sample between said angles. Meanwhile, the amorphous characteristic can be seen at $2 \theta$ angle between $0^{\circ}-20^{\circ}$ since at that angle XRD pattern of the cellulose show wide diffraction [16]. Rice husk fiber containing cellulose fiber has a peak characteristic at $2 \theta\left(^{\circ}\right)=16.2^{\circ}$ (cellulose I) in its amorphous form and $22.4^{\circ}$ (cellulose II) in its crystal form. Rice husk fiber delignified with $\mathrm{NaOH}$ can increase the intensity or crystalline structure of the rice husk fiber [15]. This is due to the loss of lignin and hemicellular content after delignification. Table 2 shows that rice husk fiber has increased CrI value after the delignification process from $62.28 \%$ to $64.98 \%$. The increased intensity of the crystalline peak identifies that crystalline cellulose had been formed as the amorphous peak shows a reduced polysaccharide structure shown through the broad peak [17].

Table 2. Characteristics of SP, SP-D, BSP-M, and BSP$\mathrm{MH}$

\begin{tabular}{cccc}
\hline \multirow{2}{*}{ Sample } & \multicolumn{2}{c}{ Characteristic Peak } & \multirow{2}{*}{ CrI (\%) } \\
\cline { 2 - 3 } & Amorph $\left(16.2^{\circ}\right)$ & Crystal $\left(22.4^{\circ}\right)$ & \\
\hline RHF & 745 & 1209 & 62.28 \\
RHF-D & 771 & 1272 & 64.98 \\
RHB-M & 208 & 297 & 42.78 \\
RHB-MH & 123 & 166 & 34.95 \\
\hline
\end{tabular}

The formation of $\mathrm{Fe}_{3} \mathrm{O}_{4}$ particles in the biocomposite was detected with a specific peak at $36^{\circ}$. This result is in accordance with the standard pattern of crystalline magnetite (JCPDS card 39-0664). In RHB- $\mathrm{MH}, \mathrm{Fe}_{3} \mathrm{O}_{4}$ particles have a peak that is larger than RHB-M since RHB-MH has smaller and evenly distributed particles affecting the diffraction of light passed on the biocomposite, causing the reading intensity to become more significant. XRD patterns in $\mathrm{RH}$ and biocomposite are shown in Figure 4.

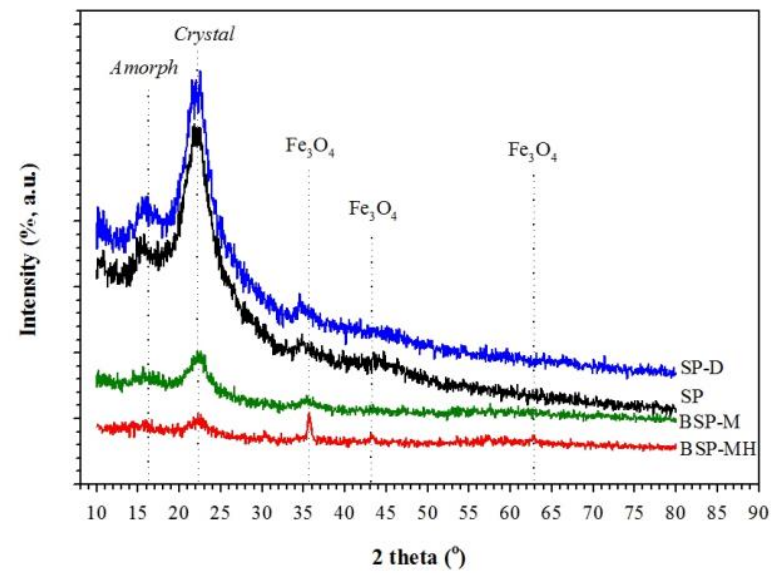

Figure 4. X-Ray Diffraction (XRD) of rice husk fiber before delignification, after delignification and magnetic nanoparticle biocomposite.

Figure 5 shows the FT-IR spectra of RH, RH-D, RHB$\mathrm{M}$, and RHB-MH. Vibration for $\mathrm{C}-\mathrm{H}$ stretching on $\mathrm{RH}$ and $\mathrm{RH}-\mathrm{D}$ is shown at the peak in the wavenumber of 2920 $\mathrm{cm}^{-1}$. For peak $570 \mathrm{~cm}^{-1}$ showing the stretching of the $\mathrm{Fe}-$ $\mathrm{O}$ component in $\mathrm{Fe}_{3} \mathrm{O}_{4}$, the peak was not detected in the $\mathrm{RH}$ and $\mathrm{RH}-\mathrm{D}$ samples. Modification of amino groups in the RHB-MH can be detected at the $1627 \mathrm{~cm}^{-1}$ peak for $\mathrm{N}-\mathrm{H}$ bending vibration. At wavenumber $1084 \mathrm{~cm}^{-1}, \mathrm{Si}-\mathrm{OH}$ and $\mathrm{O}-\mathrm{H}$ bend can be identified, and at wavelength $2920 \mathrm{~cm}^{-1}$ $\mathrm{C}-\mathrm{H}$ stretching is shown [18].

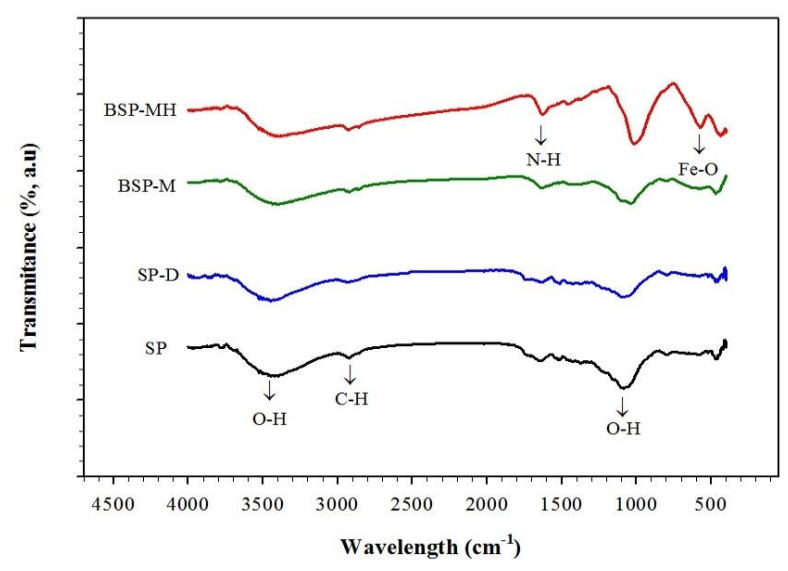

Figure 5. FT-IR spectra of rice husk fiber before delignification, after delignification and magnetic nanoparticle biocomposite 
3.2. 3.2. Adsorption of Manganese Ions $\left(\mathrm{Mn}^{2+}\right)$ with Magnetic Nanoparticle Biocomposites as an Adsorbent

In the adsorption process, it is necessary to determine the optimum contact time for the $\mathrm{Mn}^{2+}$ ions. Thus, an experiment was carried out to test out contact time using RHB-M and RHB-MH. The results obtained can be seen in Figure 6. The ability of RHB-M and RHB$\mathrm{MH}$ to bind $\mathrm{Mn}^{2+}$ ions increased during the $0-30$ minutes duration, reaching an adsorption capacity of $54.7 \mathrm{mg} / \mathrm{g}$ for RHB-M and $190.78 \mathrm{mg} / \mathrm{g}$ for RHB - MH. Furthermore, the amount of $\mathrm{Mn}^{2+}$ ion adsorbed starts to become constant at 60 minutes of the adsorption process. This is due to the saturation condition achieved, along with a dynamic equilibrium between the adsorption rate, where there are no more $\mathrm{Mn}^{2+}$ ions adsorbed or released or dissolved back into the adsorbate because the equilibrium point has been reached [19]. RHB-MH as an adsorbent is better; its absorption is 2.5 times compared to RHB-M. This is because BSP-MH has a smaller particle size (50 $\mathrm{nm}$ ) that can expand the surface of the adsorbent, high permeability, and stable mechanical and thermal properties causing better adsorption process to take place [20].

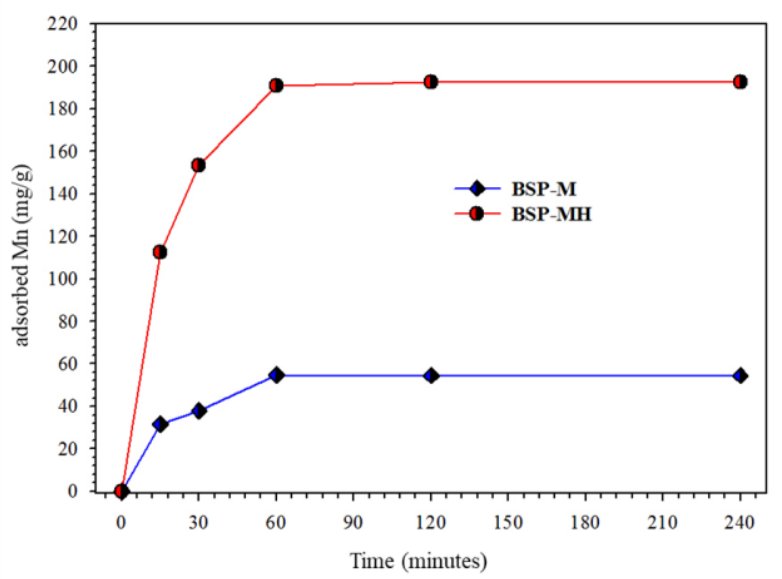

Figure 6. Graph of the capacity of Manganese $\left(\mathrm{Mn}^{2+}\right)$ ion absorption against the adsorption contact time.

Conditions: $\mathrm{pH}$ 5, $100 \mathrm{rpm}$, sample volume $200 \mathrm{~mL}$

The absorption capacity of an adsorbent is influenced by the $\mathrm{pH}$ of the solution. This is in relation to the protonation or deprotonation of the surface of the active site of the adsorbent [21, 22]. According to Huang et.al. [23], $\mathrm{pH}$ can affect the adsorbent surface charge, the degree of ionization and the species that can be absorbed in the adsorption process. For the adsorption by magnetic materials, $\mathrm{pH}$ below 5 is not carried out, since, at that $\mathrm{pH}$, Fe leaching into the solution occurs [7]. The ability of RHB-M and RHB-MH adsorbents to absorb $\mathrm{Mn}^{2+}$ ions can be seen in Figure 7.

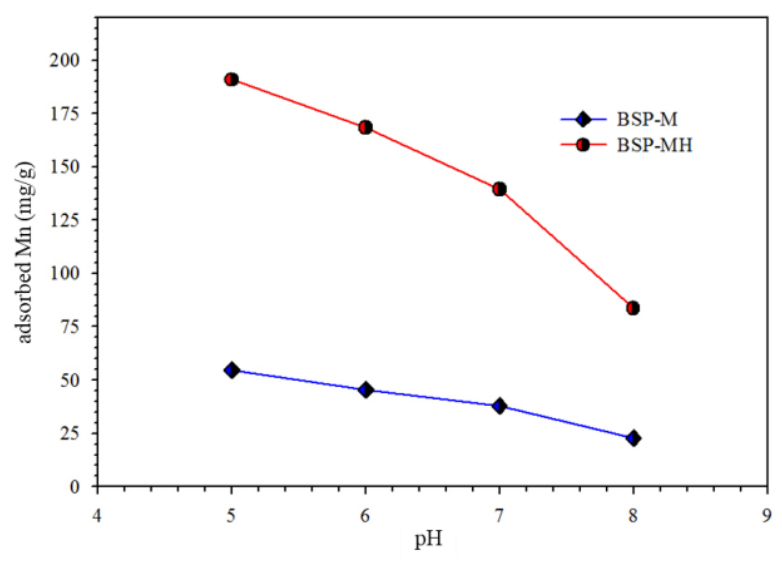

Figure 7. The relation of manganese ion $\left(\mathrm{Mn}^{2+}\right)$ adsorption capacity to solution $\mathrm{pH}$ variations with $\mathrm{RHB}-$ $\mathrm{M}$ and RHB-MH adsorbents. Conditions: $100 \mathrm{rpm}, 60$ minutes, $200 \mathrm{~mL}$ sample volume

Figure 7 shows the optimum $\mathrm{pH}$ of 5 for the two adsorbents with an absorption capacity of $54.7 \mathrm{mg} / \mathrm{g}$ and $190.8 \mathrm{mg} / \mathrm{g}$, respectively. In this condition, a dynamic equilibrium occurs between the adsorption rate, reaching the equilibrium point. At $\mathrm{pH}$ above 5 the adsorption capacity decreased due to the positively charged adsorbent surface preventing interactions with manganese ions [24]. The decrease that occurred is because the $\mathrm{Mn}^{2+}$ ion reacts with $\mathrm{NaOH}$ to form $\mathrm{MnOH}$ when the solution was set to have an alkaline or basic condition. In Figure 8, we can see the comparison of manganese ion absorption of RH-D, RHB-M, and RHB$\mathrm{MH}$ adsorbents for the same conditions. Rice husk fiber after the delignification process has an adsorption capacity of $30.27 \mathrm{mg} / \mathrm{g}$ as rice husk fiber contains about $40 \%$ cellulose. It is composed of cellulose and lignin, in which when it is delignified, it has an active - OH group that has the ability to bind ions in liquid waste.

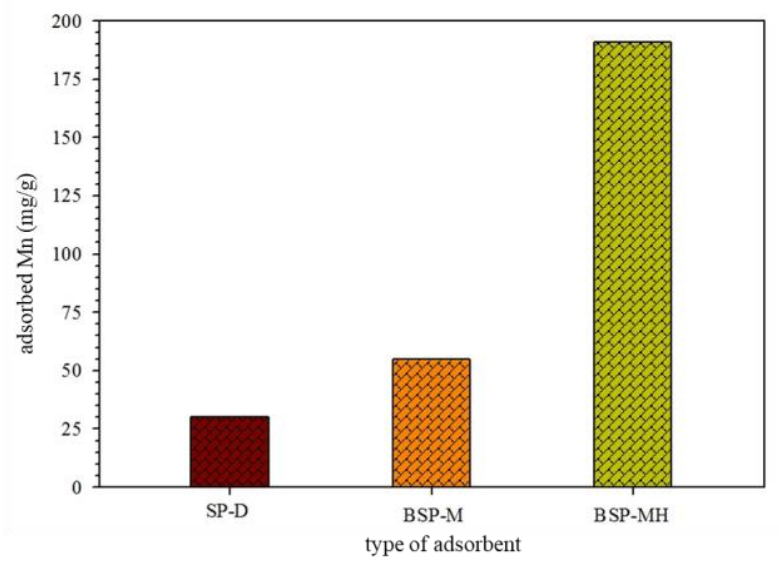

Figure 8. Comparison of manganese ion absorption for different types of adsorbents. Conditions: $\mathrm{pH}$ 5, $100 \mathrm{rpm}$, 60 minutes, $200 \mathrm{~mL}$ sample volume

Under the same conditions as the adsorption process, TSS was calculated for different $\mathrm{pH}$ conditions of the solution, which were $5,6,7$, and 8 . Figure 9 shows that at $\mathrm{pH} 8$, the highest TSS reduction occurred; for RHB-M at 
$60.2 \%$ and RHB-MH at $90.3 \%$. This is because, in the condition of a basic solution, the coagulation process of organic and inorganic compounds in peat water occurs optimally, causing the suspended substances to form flocks, which are then coagulated. The occurrence of sediment in these basic conditions helps increase the percentage of TSS reduction.

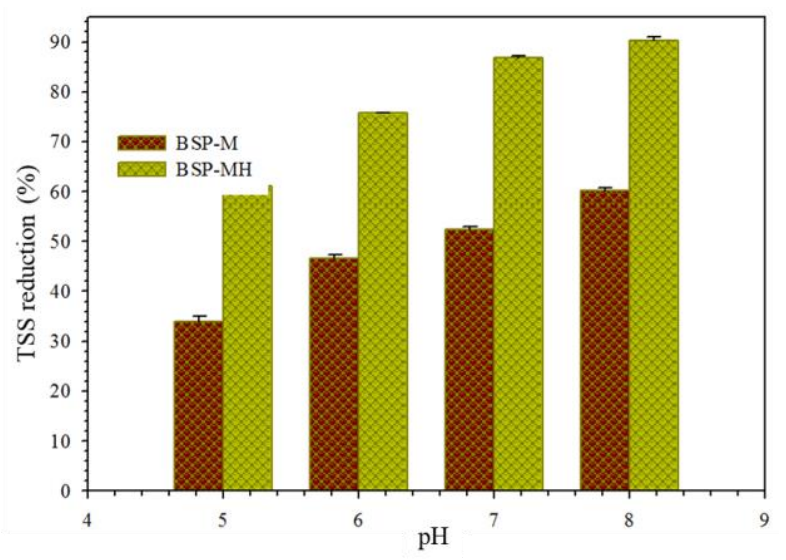

Figure 9. Effectiveness of TSS reduction under varying pH. Conditions: $100 \mathrm{rpm}, 60$ minutes, $200 \mathrm{~mL}$ sample volume

Descriptions:

BSP-M = RHB-M

$\mathrm{BSP}-\mathrm{MH}=\mathrm{RHB}-\mathrm{MH}$

\section{Conclusion}

Biocomposite produced from a combination of rice husk fiber and magnetic nanoparticles through the solvothermal method has a good adsorption ability for manganese ions in peat water. The largest adsorption capacity of the biocomposite synthesized with hexanediamine was $190.78 \mathrm{mg} / \mathrm{g}$. In addition to the ability of adsorption, the resulting biocomposite is able to reduce TSS in solution up to $61.6 \%$ at $\mathrm{pH}$ 5. Magnetic nanoparticle biocomposite made from the biomass can be developed as an adsorbent for other metal ions. The processes required in the synthesis and adsorption are simple and effective.

\section{Acknowledgments}

The authors would like to express gratitude for the 2019 Research Student Creativity Program (PKM) Grant from the Ministry of Research, Technology and Higher Education, Republic of Indonesia.

\section{References}

[1] James C. Williams and Edgar A. Starke, Progress in structural materials for aerospace systems11The Golden Jubilee Issue-Selected topics in Materials Science and Engineering: Past, Present and Future, edited by S. Suresh, Acta Materialia, 51, 19, (2003) 5775-5799

https://doi.org/10.1016/j.actamat.2003.08.023
[2] J. W. Kaczmar, K. Pietrzak and W. Włosiński, The production and application of metal matrix composite materials, Journal of Materials Processing Technology, 106, 1, (2000) 58-67 https://doi.org/10.1016/S0924-0136(00)00639-7

[3] Flake C. Campbell, Structural Composite Materials, ASM International, 2010.

[4] Arsalan Hekmati and Rasoul Hekmati, Double pancake superconducting coil design for maximum magnetic energy storage in small scale SMES systems, Cryogenics, 80, (2016) 74-81 https://doi.org/10.1016/j.cryogenics.2016.09.009

[5] Yunfei Zhao, Mingfeng Cao, John F. McClelland, Zengyi Shao and Meng Lu, A photoacoustic immunoassay for biomarker detection, Biosensors and Bioelectronics, 85, (2016) 261-266 https://doi.org/10.1016/j.bios.2016.05.028

[6] Desiana Wuryanti and Edi Suharyadi, Studi Adsorpsi Logam Co(II), Cu(II), dan Ni(II) dalam Limbah Cair Buatan Menggunakan Adsorben Nanopartikel Magnetik $\mathrm{Fe}_{3} \mathrm{O}_{4}$ dan $\mathrm{ZnFe}_{2} \mathrm{O}_{4}$, Jurnal Fisika Indonesia, $20,2,(2016) 28-35$

[7] Iryanti F. Nata, Nermeen S. El-Safory and ChengKang Lee, Carbonaceous Materials Passivation on Amine Functionalized Magnetic Nanoparticles and Its Application for Metal Affinity Isolation of Recombinant Protein, ACS Applied Materials \& Interfaces, 3, 9, (2011) 3342-3349 https://doi.org/10.1021/am200453e

[8] Leyu Wang, Jie Bao, Lun Wang, Fang Zhang and Yadong Li, One-Pot Synthesis and Bioapplication of Amine-Functionalized Magnetite Nanoparticles and Hollow Nanospheres, Chemistry - A European Journal, 12, 24, (2006) 6341-6347 https://doi.org/10.1002/chem.200501334

[9] B. H. Hameed and A. A. Ahmad, Batch adsorption of methylene blue from aqueous solution by garlic peel, an agricultural waste biomass, Journal of Hazardous Materials, 164, 2, (2009) 870-875 https://doi.org/10.1016/j.jhazmat.2008.08.084

[10] I. A. W. Tan, A. L. Ahmad and B. H. Hameed, Adsorption isotherms, kinetics, thermodynamics and desorption studies of 2,4,6-trichlorophenol on oil palm empty fruit bunch-based activated carbon, Journal of Hazardous Materials, 164, 2, (2009) 473482 https://doi.org/10.1016/j.jhazmat.2008.08.025

[11] Hala Ahmed Hegazi, Removal of heavy metals from wastewater using agricultural and industrial wastes as adsorbents, HBRC Journal, 9, 3, (2013) 276-282 https://doi.org/10.1016/j.hbrcj.2013.08.004

[12] Emiliano M. Ciannamea, Pablo M. Stefani and Roxana A. Ruseckaite, Medium-density particleboards from modified rice husks and soybean protein concentrate-based adhesives, Bioresource Technology, 101, 2, (2010) 818-825 https://doi.org/10.1016/j.biortech.2009.08.084

[13] Iryanti Fatyasari Nata, Giyanto Wijaya Salim and Cheng-Kang Lee, Facile preparation of magnetic carbonaceous nanoparticles for $\mathrm{Pb} 2+$ ions removal, Journal of Hazardous Materials, 183, 1, (2010) 853-858 https://doi.org/10.1016/j.jhazmat.2010.07.105 
[14] Iryanti Fatyasari Nata, Manthiriyappan Sureshkumar and Cheng-Kang Lee, One-pot preparation of amine-rich magnetite/bacterial cellulose nanocomposite and its application for arsenate removal, RSC Advances, 1, 4, (2011) 625-631 https://doi.org/10.1039/C1RA00153A

[15] Saeedeh Hashemian, Seyed Hossein Hosseini, Hamila Salehifar and Khaterah Salari, Adsorption of Fe(III) from Aqueous Solution by Linde Type-A Zeolite, American Journal of Analytical Chemistry,, 4, 7A, (2013) 123-126 https://doi.org/10.4236/ajac.2013.47A017

[16]Risfidian Mohadi, Nurlisa Hidayati and Aldes Lesbani, Adsorption Desorption of Chromium (III) Ion on Cellulose from Wood Powder, International Journal of Science and Engineering, 7, 1, (2014) 77-80 https://doi.org/10.12777/ijse.7.1.77-80

[17] L. Ghali, S. Msahli, M. Zidi and F. Sakli, Effect of pretreatment of Luffa fibres on the structural properties, Materials Letters, 63, 1, (2009) 61-63

https://doi.org/10.1016/j.matlet.2008.09.008

[18] I. F. Nata, M. D. Putra, D. Nurandini, C. Irawan, R. Fitriani and M. D. Isnaini, Rice Husk Fiber Magnetic Nanoparticle Biocomposites: Preparation and Characterization, IOP Conference Series: Earth and Environmental Science, 175, (2018) 012005 https://doi.org/10.1088/1755-1315/175/1/012005

[19] P. Waranusantigul, P. Pokethitiyook, M. Kruatrachue and E. S. Upatham, Kinetics of basic dye (methylene blue) biosorption by giant duckweed (Spirodela polyrrhiza), Environmental Pollution, 125, 3, (2003) 385-392 https://doi.org/10.1016/S0269-7491(03)00107-6

[20]Wei Wu, Quanguo He and Changzhong Jiang, Magnetic Iron Oxide Nanoparticles: Synthesis and Surface Functionalization Strategies, Nanoscale Research Letters, 3, 11, (2008) 397 https://doi.org/10.1007/s11671-008-9174-9

[21] Soodamani Periyasamy, Venkatrajan Gopalakannan and Natrayasamy Viswanathan, Fabrication of magnetic particles imprinted cellulose based biocomposites for chromium(VI) removal, Carbohydrate Polymers, 174, (2017) 352-359

https://doi.org/10.1016/j.carbpol.2017.06.029

[22] Ying Zhang, Jiaying Zhao, Zhao Jiang, Dexin Shan and Yan Lu, Biosorption of Fe(II) and Mn(II) Ions from Aqueous Solution by Rice Husk Ash, BioMed Research International, 2014, (2014) 10 https://doi.org/10.1155/2014/973095

[23]Yao-Hui Huang, Yu-Jen Shih and Chia-Chi Chang, Adsorption of fluoride by waste iron oxide: The effects of solution $\mathrm{pH}$, major coexisting anions, and adsorbent calcination temperature, Journal of Hazardous Materials, 186, 2, (2011) 1355-1359 https://doi.org/10.1016/j.jhazmat.2010.12.025

[24]An-Hui Lu, E. L Salabas and Ferdi Schüth, Magnetic Nanoparticles: Synthesis, Protection, Functionalization, and Application, Angewandte Chemie International Edition, 46, 8, (2007) 1222-1244 https://doi.org/10.1002/anie.200602866 